\title{
Comparison of tensile strength and fracture toughness under mode I and II loading of co-cured and co-bonded CFRP joints
}

\author{
F. Moroni, A. Pirondi \\ Dipartimento di Ingegneria e Architettura, Università di Parma, Parco Area delle Scienže, 181/A, 43124 Parma, Italy \\ fabrizio.moroni@unipr.it,alessandro.pirondi@unipr.it \\ C. Pernechele, A. Gaita, L. Vescovi \\ Dallara Automobili, Via Provinciale, 33, 43040 Varano Melegari (PR), Italy \\ c.pernechele@dallara.it,.a.gaita@dallara.it,l.vescovi@dallara.it
}

\begin{abstract}
Carbon-Fiber Reinforced Polymer (CFRP) parts are joined mainly using adhesive bonding because, differently from fastening, additional parts (hence weight saving) and through holes (that are always detrimental for the strength due to the possibility of developing damage into the composite) are not necessary. Additionally, it allows for large connection areas, thus distributing stresses better than fastened connections. However, since CFRP can be joined by co-curing, the choice of bonding has to be evaluated as an alternative by a trade-off in terms of strength and durability, compared to cost and manufacturing time and complexity. In this work, a comparison between co-cured and co-bonded CFRP is done with respect to tensile strength and mode I and mode II fracture toughness, in order to understand whether cobonding guarantees the same performance of a co-cured composite part.
\end{abstract}

KEYWORDS. Carbon-Fiber Reinforced Polymer; bonded joints; fracture toughness.

\begin{abstract}
OPEN $\bigcirc$ ACCESS
Citation: F. Moroni, A. Pirondi, C. Pernechele, A. Gaita, L. Vescovi Comparison of tensile strength and fracture toughness under mode I and II loading of co-cured and co-bonded CFRP joints, Frattura ed Integrità Strutturale, 47 (2019) 294-302.

Received: 29.08.2018

Accepted: 17.10 .2018

Published: 01.01.2019

Copyright: (C) 2019 This is an open access article under the terms of the CC-BY 4.0, which permits unrestricted use, distribution, and reproduction in any medium, provided the original author and source are credited.
\end{abstract}

\section{INTRODUCTION}

7 he joining of composite laminates is alternatively made by mechanical fastening, bonding or co-curing, as testified from the large number of studies performed on the topic [1-7], while welding is confined to thermoplastic matrix composites. Fastening is preferred where decoupling for inspection and/or maintenance is necessary, but it requires the drilling of a hole through the composite that generates a fiber discontinuity, in turn affecting bearing and shear strength of the component. On the other hand, bolts and holes are not necessary when composite laminates are joined by bonding or co-curing, while the joint strength is typically limited by the onset of debonding or delamination. For this reason, the fracture toughness is a property of utmost importance to assess for the design of the connection, but it is also important to know it to compare different design solutions in terms of strength versus cost, manufacturing time and complexity. Four 
different manufacturing routes can be used for bonding composite parts: i) secondary bonding; ii) co-bonding; iii) co-curing (with or without adhesive). The last two methods are generally preferred over the first one for bonding small- to mediumsize components because of the smaller number of manufacturing steps [8]. However, the majority of papers in the literature test fracture behavior of secondary bonded joints. A comparison of the fracture toughness of co-bonded and joints cocured without adhesive is generally missing, too. Most of the times adherents are made by a cross- and/or angle ply stacking of unidirectional (UD) plies, while in several applications wowen, satin or braided textiles are used for manufacturing purposes. This paper is therefore aimed at testing and comparing co-cured (without adhesive) and co-bonded joints of textile CFRP adherents. The experiments concern the tensile strength and the mode I and mode II fracture toughness, to assess whether co-bonding can guarantee the same performance of a co-cured composite joint.

\section{EXPERIMENTS}

\section{Materials and specimen manufacturing}

satin-weave (5H) carbon fiber C280 T1100 12K, pre-impregnated with 38\% 2573 epoxy resin, was supplied by Toray with a ply nominal thickness of $0.3 \mathrm{~mm}$. The structural adhesive used in this work is AF 163-2U Scotch-Weld thermosetting modified epoxy, supplied by $3 \mathrm{M}$ in the form of unsupported film with a $0.15 \mathrm{~kg} / \mathrm{m}^{2}$ mass and 0.14 $\mathrm{mm}$ nominal thickness. Mechanical properties from the suppliers technical datasheets are reported in Tab. 1.

\begin{tabular}{llll}
\hline Material & & Modulus of elasticity (GPa) & Tensile Strength (MPa) \\
T1100 CF + & $0^{\circ}$ tensile & 89 & 1900 \\
2573 epoxy & $90^{\circ}$ tensile & 87 & 1740 \\
resin & $0^{\circ}$ compressive & 76 & 800 \\
adherent & $90^{\circ}$ compressive & 80 & 740 \\
& $0^{\circ}$ Flexural & 75 & 1060 \\
& $0^{\circ}$ ILSS & - & 74 \\
AF 163 adhesive film & - & 73 \\
\hline
\end{tabular}

Table 1: Properties at environmental temperature of the materials used in this work.

The composite joint was co-cured a $130^{\circ} \mathrm{C}$ for $120 \mathrm{~min}$ in a vacuum bag with an applied external pressure of 6 bars while, in the case of co-bonded joint, the adhesive film was placed on a cured, sandpapered and cleaned with acetone CFRP adherent, then pre-preg plies were laid over the adhesive and the resulting layup was consolidated at $130^{\circ} \mathrm{C}$ for $120 \mathrm{~min}$ in a vacuum bag with applied external pressure of 6 bars.

The experimental plan includes the following tests:

- TRAZ-BJ: tensile test on butt-bonded cylindrical joints, in order to extract the average tensile strength of the adhesive used in a joint;

- TRAZ-CI: tensile test on cylinders of CFRP, stressed in direction 3 (perpendicular to the lamination plane) in order to extract the ILTS (InterLaminar Tensile Strength);

- TRAZ-CE: tensile test on cylinders of composite material, stressed in direction 3 (perpendicular to the lamination plane) in order to extract the elastic module in direction 3 of the laminate;

- DCB: mode I delamination/debonding test

- ENF: mode II delamination/debonding test

\section{ILTS and co-bonded joint average tensile strength}

The nominal geometry of TRAZ-CI and TRAZ-BJ specimens is shown in Fig. 1(a) and (b), respectively, that comply with the ASTM D 7291 standard. The threaded aluminum ends are bonded to the composite using 3M $9323 \mathrm{~A} / \mathrm{B}$ two-part, structural epoxy adhesive, which is commonly used by Dallara in cold bonding of composites and it is generally stronger than the composite itself. The specimens are attached to the testing machine (MTS 810 with Trio Sistemi e Misure RT3 controller) using two universal joints for self-alignment. In the case of TRAZ-CI tests, beside the extensometer three strain gages are placed at angles of $120^{\circ}$ (Fig. 2) in order to have the value of the out-of-plane Young's modulus measured on the composite, but also to monitor that the strain is uniform across the gage section. The tests have been conducted under displacement control at a crosshead displacement rate of $0.002 \mathrm{~mm} / \mathrm{sec}$. 

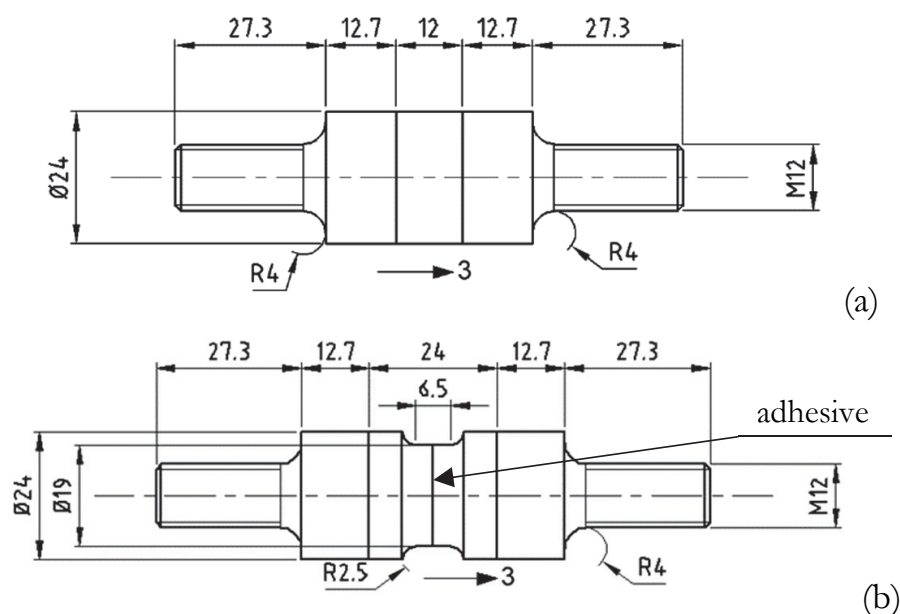

(a)

Figure 1: Nominal size of TRAZ-CI (a) and TRAZ-BJ (b) speciments

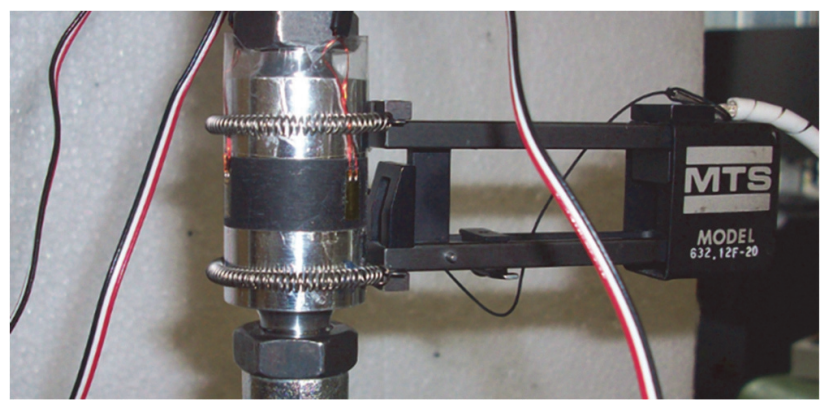

Figure 2: Experimental setup of a TRAZ-CI test.

Fracture toughness testing

The same specimen is used for both DCB and ENF tests and it is shown in Fig. 3. Each adherent is made of 19 aligned along the $0^{\circ}$ fiber direction.
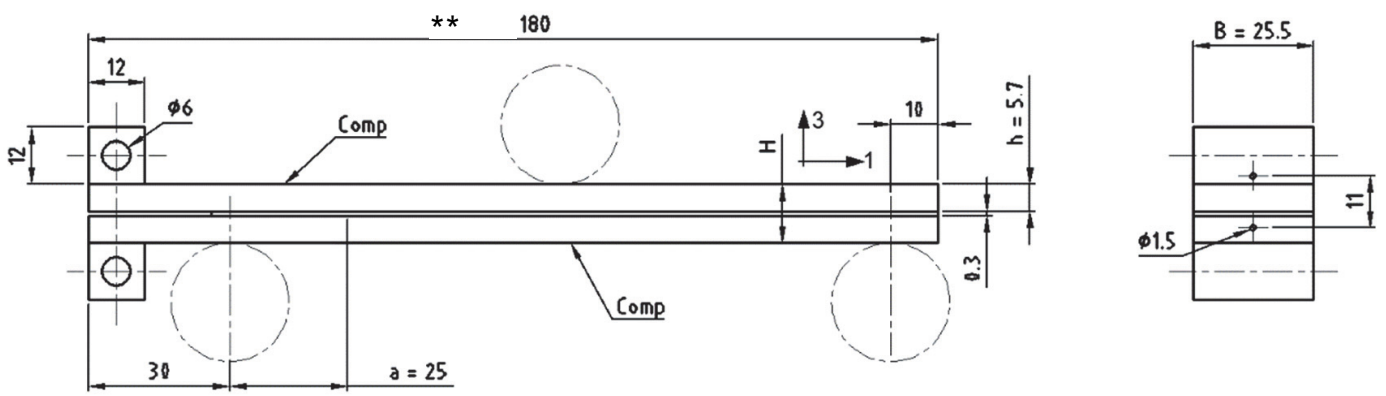

Figure 3: Nominal dimensions of DCB specimens. ${ }^{*} \mathrm{~W}=150$ (DCB) or $180 \mathrm{~mm}$ (ENF). Dashed-dotted circles represent the ENF supports and load application points.

Co-bonded joints present an insert of a sheet of non-stick material at one side to create the starter crack. However, since the crack tip radius depends on the thickness of the non-stick sheet, fatigue precracking under mode I loading is performed to extend the crack a few millimeters. Fracture tests are performed under displacement control at a displacement rate of 2.5 $\mathrm{mm} / \mathrm{min}$, with partial unloadings for the evaluation of the compliance and, in turn, of the crack length and of the value of $\mathrm{G}_{\mathrm{I}}, \mathrm{G}_{\mathrm{II}}$ (strain energy release rate under mode I or mode II loading, respectively) as a function of crack length (R-curve). The value of $\mathrm{G}_{\mathrm{I}}, \mathrm{G}_{\mathrm{II}}$ are evaluated at each unloading point by FEM (Finite Element Modelling). The simulations are performed using ABAQUS 6.13 software. Joints are modeled using 2D plane strain models; boundary condition and loads (F) are applied as shown in Fig. 4 a) and b). 


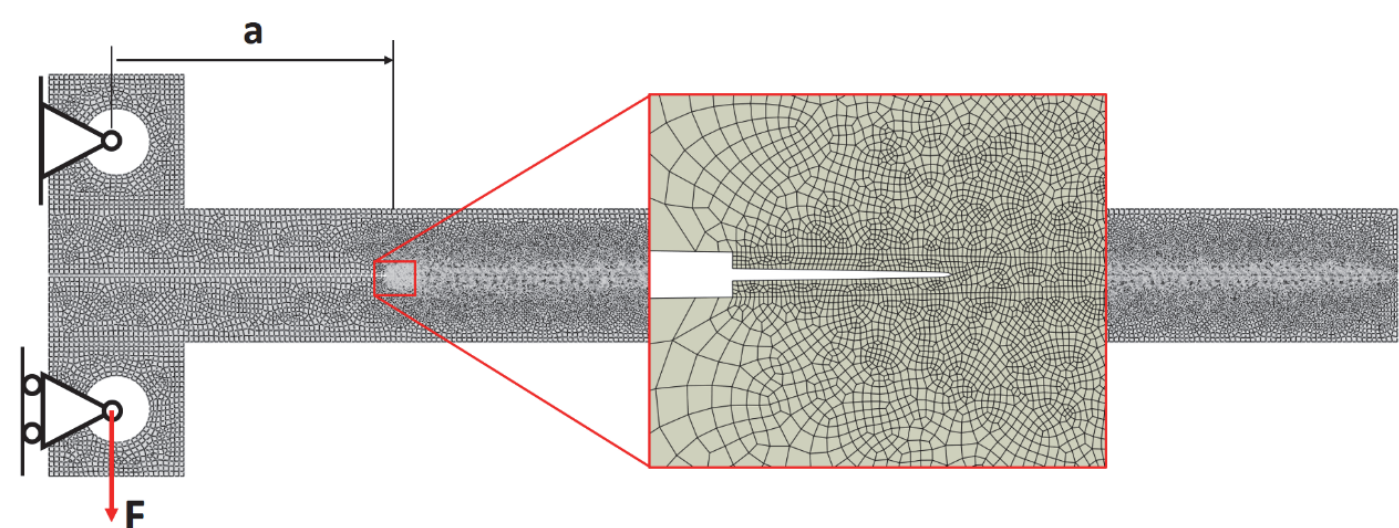

a)

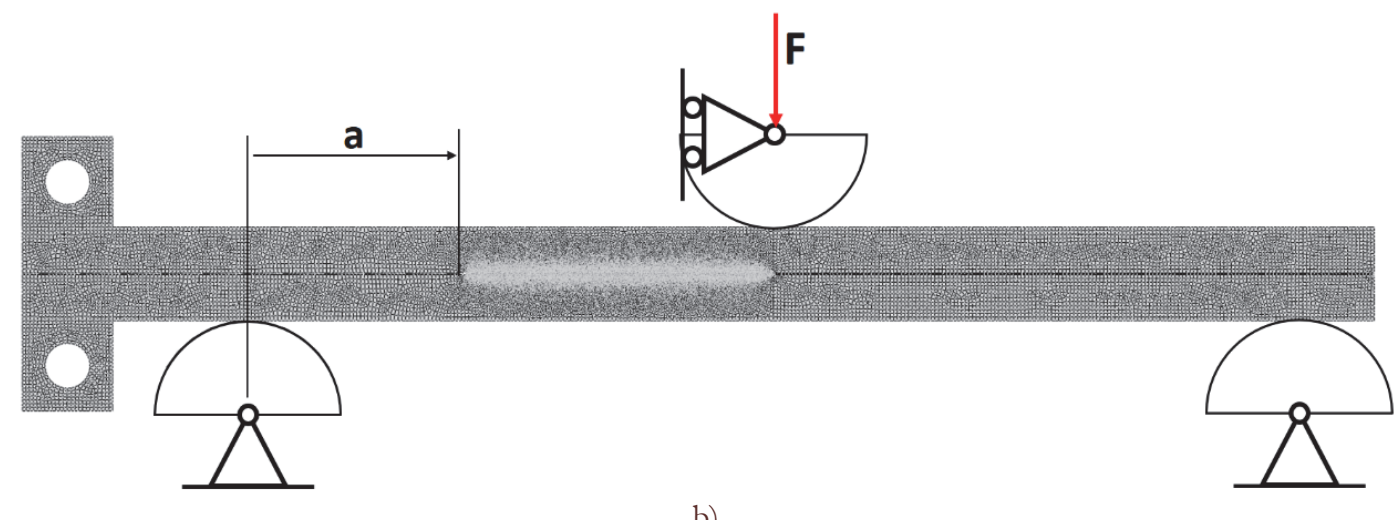

b)

Figure 4: Finite element models used to obtain the G values for DCB (a) and ENF (b) joints. A detailed view of the mesh refinement is also reported for the DCB model.

Quadrangular elements are used; the mesh size in the adherends ranges between $0.4 \mathrm{~mm}$ and $0.02 \mathrm{~mm}$, while in the adhesive layer it ranges between $0.03 \mathrm{~mm}$ and $0.02 \mathrm{~mm}$. A linear elastic behavior is assigned to the adherends and adhesive, using the mechanical properties reported in Tab. 1. The values of $G_{I}$ and $G_{I I}$ are obtained as the average of the J-integral output in 7 contours surrounding the crack tip. Also the crack-length vs. compliance relationship is evaluated numerically by FEM and input to the test control software. Three-point bending experiments were performed for the identification of the flexural and shear modulus of the composite adherent, to be used in FE simulations. Since in ENF tests the crack is not open and the compliance is less sensitive to crack length changes than in DCB tests, the crack tip position was evaluated at unloading points during the test by DIC (Digital Image Correlation) on the specimen side. The DIC values of crack length were then compared for validation to crack lengths obtained by inverse FE analysis of the unloading compliance. However, in ENF no R-curve was detected due to unstable crack propagation from the initial length to below the loading point. Co-cured composite specimens have the same dimensions and methodologies of the co-bonded ones but without using the adhesive film. Also, the overall thickness is $13 \mathrm{~mm}$ instead of $5.7 \times 2=11.4 \mathrm{~mm}$ due to a small excess of resin in the laminate. Test conditions for mode I or mode II delamination are the same of co-bonded joints. Five repetitions were done for tensile tests and three repetitions for fracture tests.

\section{RESULTS AND DISCUSSION}

\section{Tensile strength}

$\mathrm{R}$ esults will be presented scaled with respect to the tensile strength of the co-cured CFRP for the sake of confidentiality. Therefore, diagrams show normalized values denoted as $S_{\max \_n o r m}$ and for co-cured CFRP the average value of $S_{\text {max_norm }}$ is equal to 1 . For analogous reasons, the value of force in force-opening diagrams is normalized with respect to the maximum force of the same test, $\mathrm{F}_{\max }$. 
The diagram of Fig. 5 shows the results of the 5 repetitions done with TRAZ-CI test specimen. The coefficient of variation (i.e. ratio of std. deviation to average) is $5.6 \%$. Also the deformations at failure are pretty close to each other, that is a sign of a good reproducibility of the tests. The rupture surface is shown in Fig. 6, where it is evident the interlaminar failure mode that occurs between the two plies closest to the bonded interface with the aluminum attachments. This type of failure was detected in all the repetitions of the test.

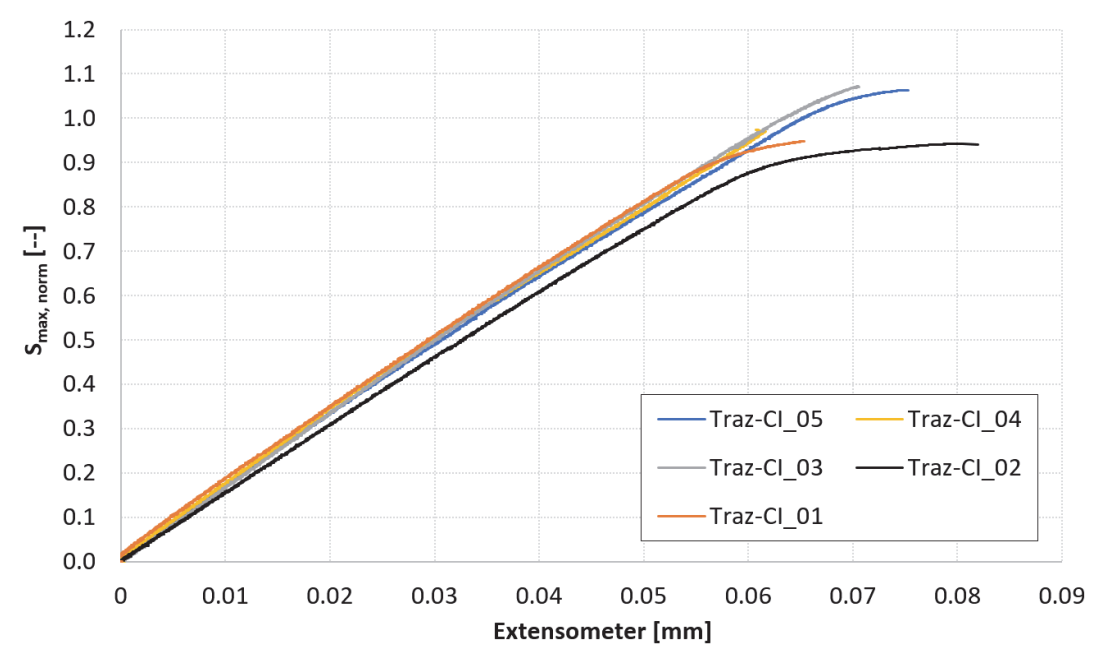

Figure 5: Results of TRAZ-CI tests.

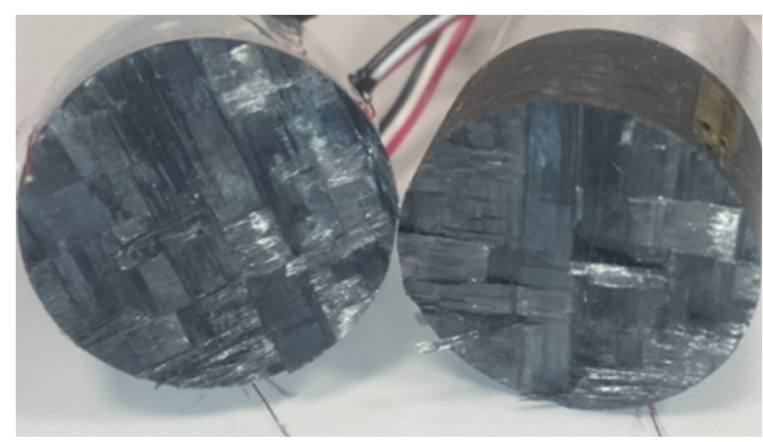

Figure 6: Example of rupture surface of TRAZ-CI tests.

The diagram of Fig. 7 shows the results of the 5 repetitions done with TRAZ-BJ test specimen. The average value of strength is just the $68.5 \%$ of the average of TRAZ-CI tests. The coefficient of variation is $6.8 \%$ in this case. Also the deformation at failure are pretty close to each other, that is a sign of a good reproducibility of the tests.

The rupture was always interlaminar in the composite and it occurred close to the root of the fillet between the reduced gage section and the specimen ends as shown in Fig. 8. The location of the failure and the lower value with respect to the TRAZ-CI tests can be related to both a slight stress concentration at the fillet root and to a possible damage caused by the tooling of the specimen done to reduce the gage section diameter. Unfortunately, this kind of failure does not allow to assess the strength of the adhesive in co-bonded joints, therefore a further TRAZ-BJ test has been designed were the threaded aluminum ends are bonded each other with the adhesive film (Fig. 9). The $S_{\max , \text { norm }}$ is in this case 1.21 times the TRAZ-CI tests with a coefficient of variation of $3.9 \%$. Failure was always cohesive in the adhesive layer. From the TRAZ-BJ (adhesive only) test it can be concluded that the tensile strength of the adhesive used here is higher than the ILTS of the composite. On the other hand, attention has to be paid in case of notches obtained by tooling operations on composite, since the comparison of TRAZ-CI and TRAZ-BJ tests it turns out a reduction of about $1 / 3$ of the ILTS.

\section{Fracture toughness}

For the sake of confidentiality, results are scaled with respect to the mode I or mode II fracture toughness of the co-cured CFRP, respectively. Therefore, normalized values denoted as $\mathrm{G}_{\mathrm{I}_{\_} \text {norm }}$ and $\mathrm{G}_{\text {II_norm }}$ are shown in diagrams. The value of force in force-opening diagrams is normalized, too, with respect to the maximum force of the same test, $\mathrm{F}_{\max }$. 
An example of force vs. opening behavior and fracture surface of co-cured DCB test is shown in Fig. 10. In some specimens, a marked ply bridging was found due to the development of multiple delaminations. This phenomenon induces a greater strain energy release, see the diagram of Fig. 11: for all the three specimens, the propagation of the crack begins at about the same $G_{I}$ but afterwards, for the specimen DCB_CC_C01_01 the value of G grows slightly and stabilizes around a 20\% higher value, while in the other two samples it increases more markedly (Fig. 11).

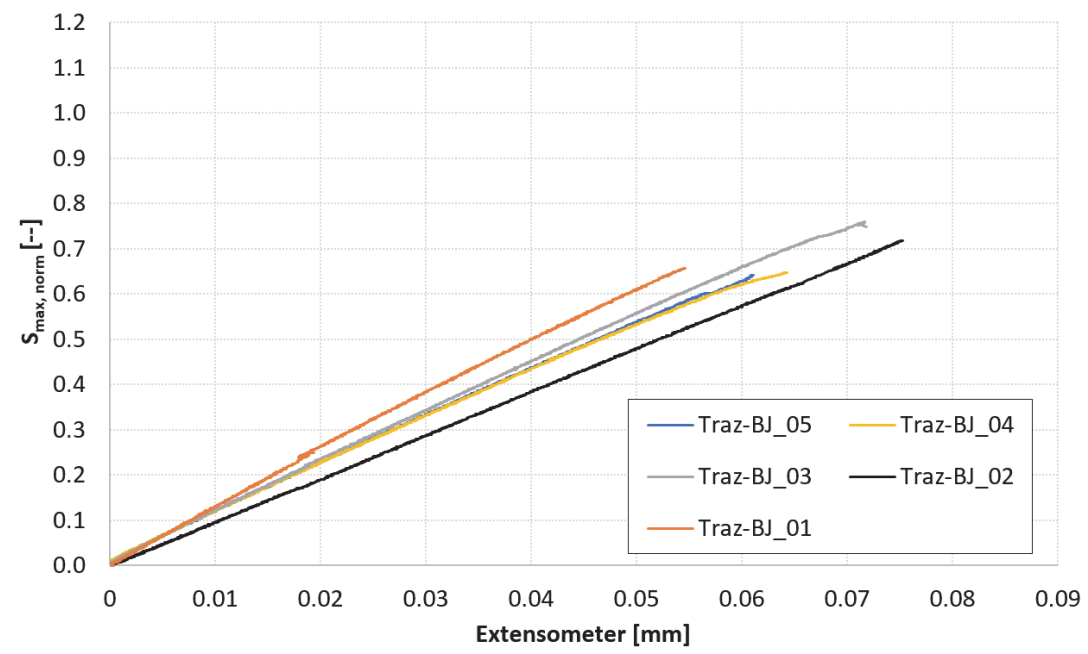

Figure 7: Results of TRAZ-BJ tests.

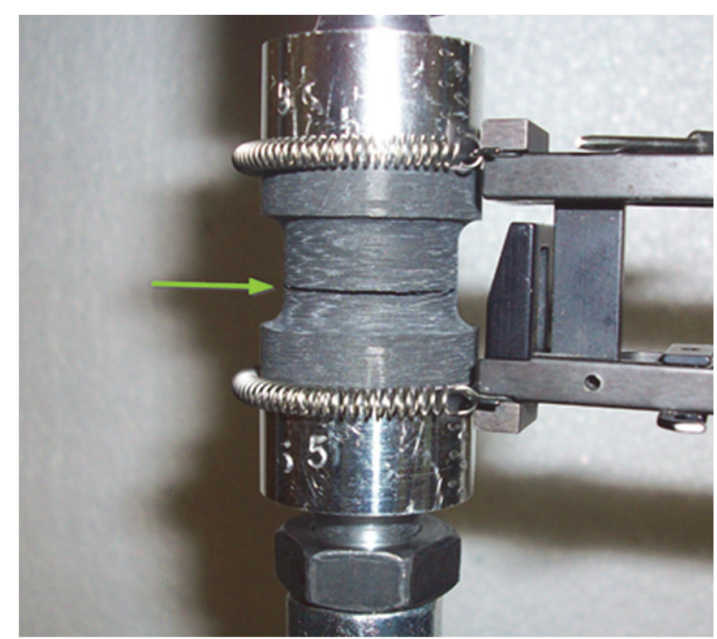

Figure 8: Example of rupture location of TRAZ-BJ tests.

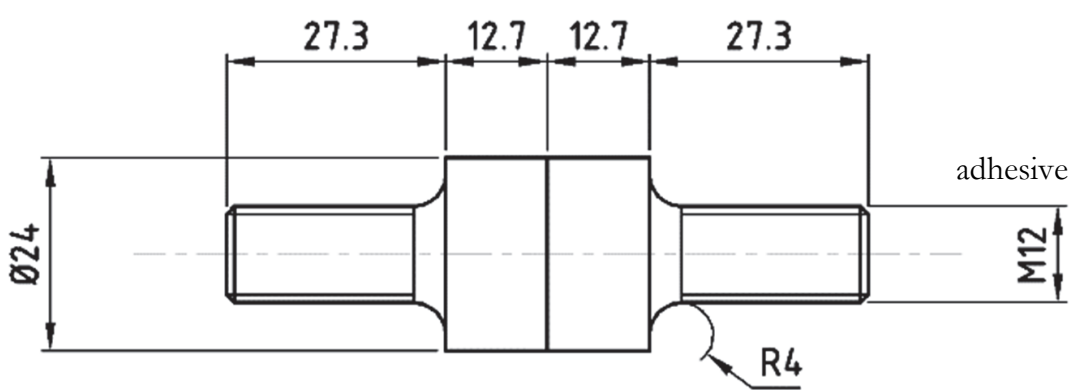

Figure 9: TRAZ-BJ (adhesive only) test geometry. 
The Force vs. opening behavior and fracture surface of co-cured ENF are shown in Fig. 12. Only one test was available at the time of writing this article. An example of Force vs. opening behavior and fracture surface of co-bonded DCB tests is shown instead in Fig.13.

The examination of the fracture surface shows that the propagation of the defect starts in the adhesive and then jumps between composite plies, possibly with multiple delaminations. By comparing the image of the fracture surface and the $\mathrm{G}_{\mathrm{I}}$ vs crack length diagram, it is therefore possible to distinguish the fracture toughness values relative to propagation inside the adhesive from those related to propagation inside the composite material, see Fig. 14. The value of $\mathrm{G}_{\mathrm{Ic}}$ and, in general the trend of the R-curve, are lower than those of co-cured CFRP specimens.
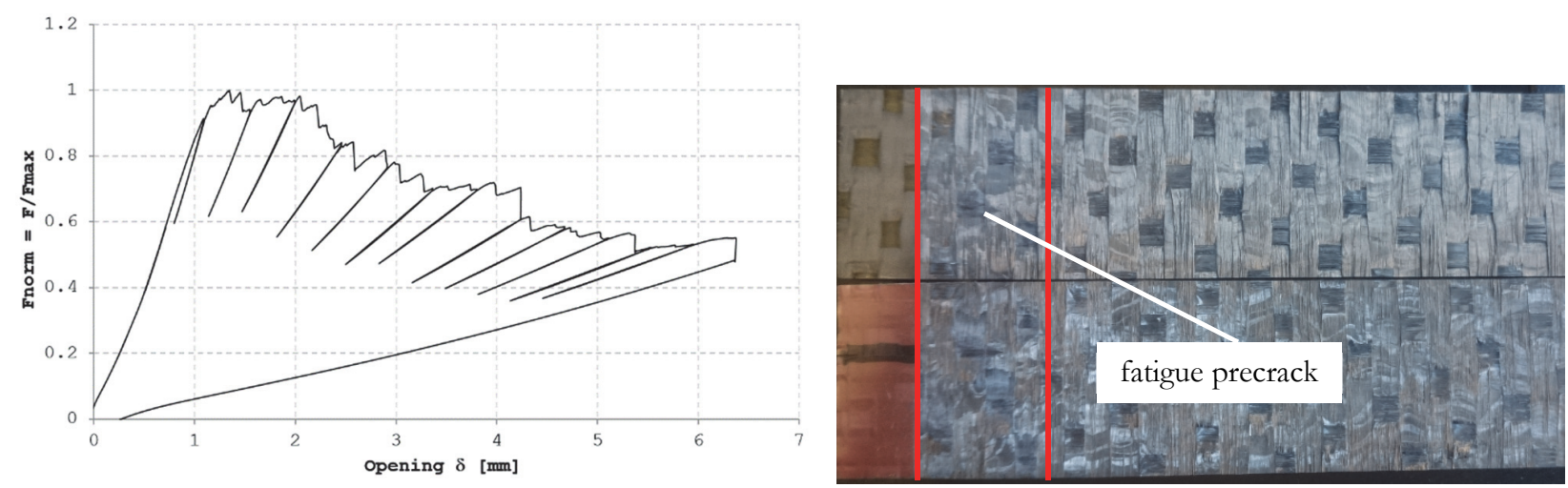

Figure 10: Example of force vs. opening behavior and fracture surface of massive CFRP DCB tests.

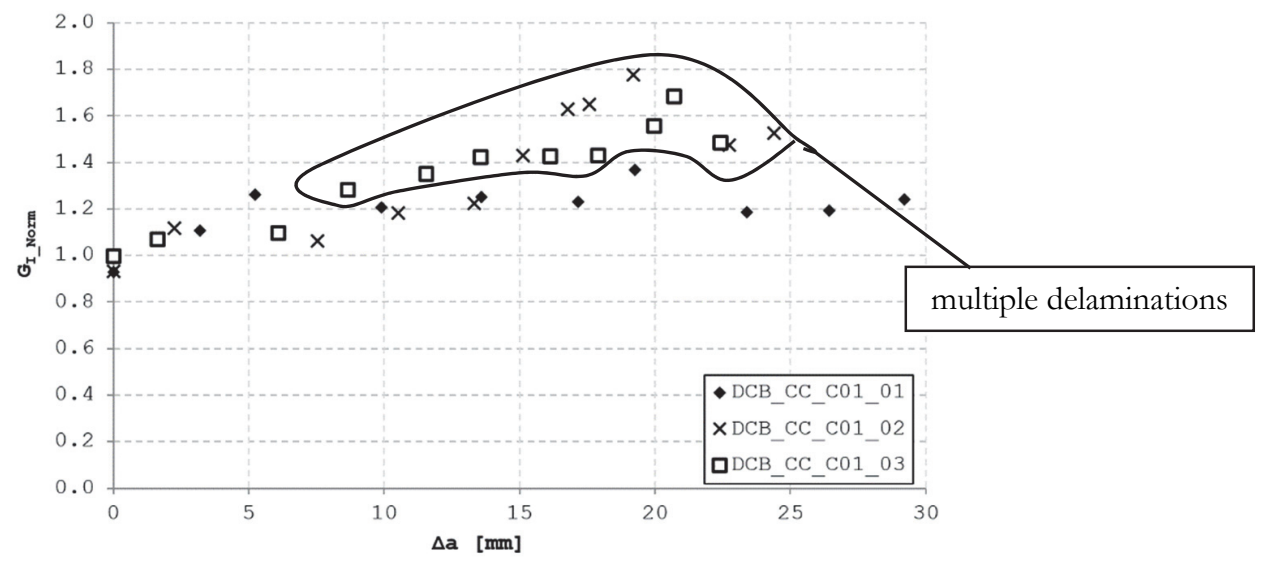

Figure 11: Mode I R-curve of co-cured CFRP tests.
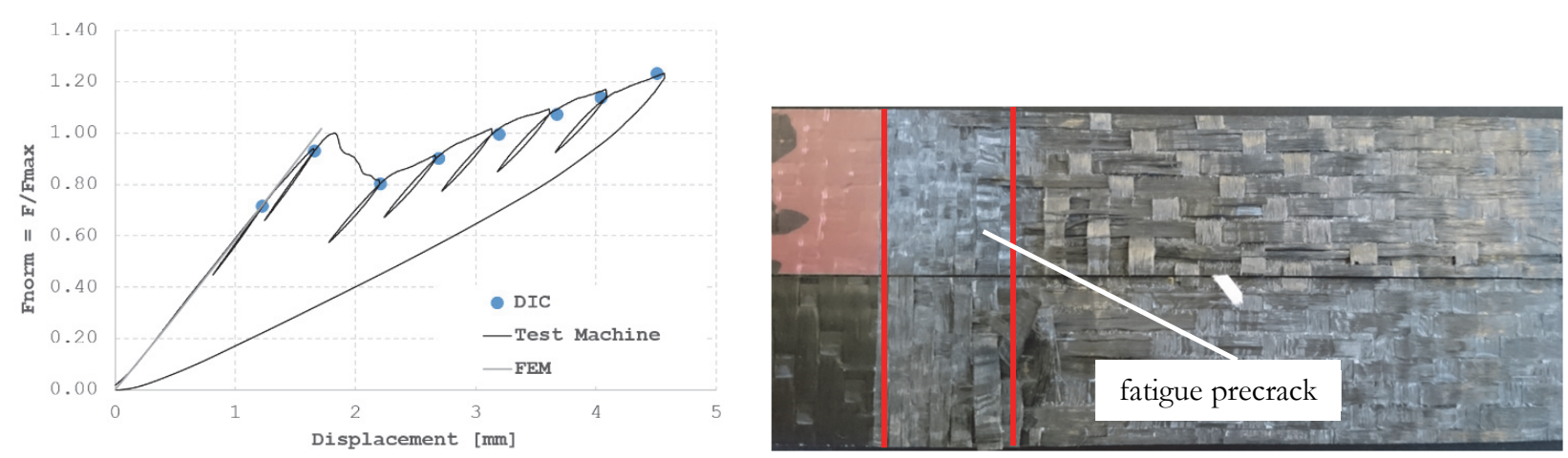

Figure 12: Example of force vs. opening behavior and fracture surface of co-cured CFRP ENF tests. 

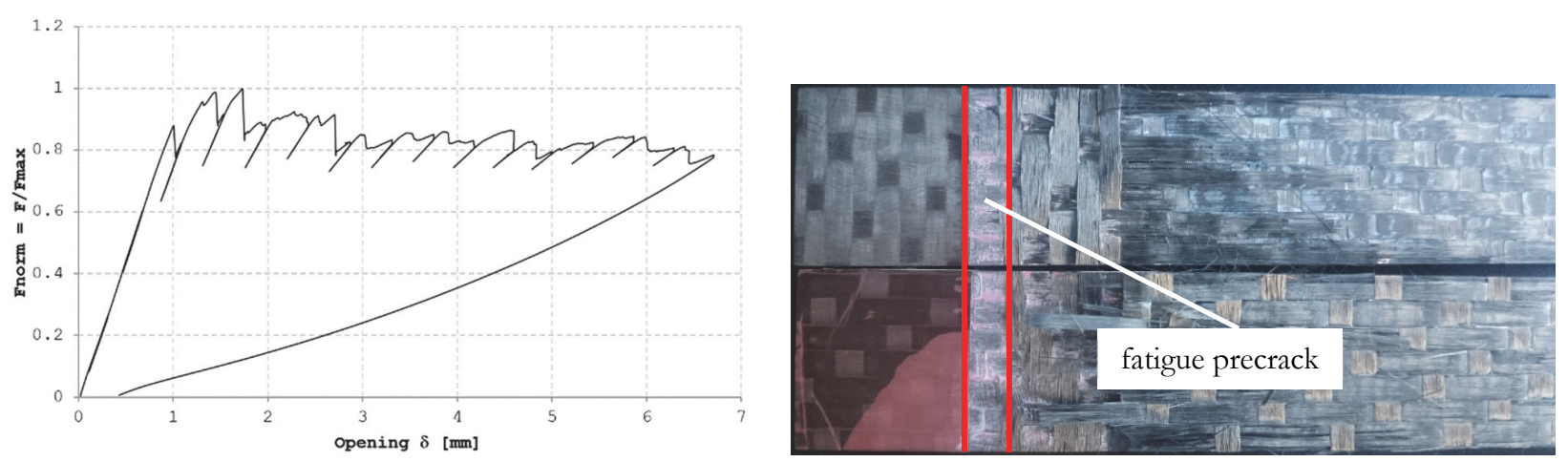

Figure 13: Example of force vs. opening behavior and fracture surface of CFRP-CFRP bonded joint DCB tests.

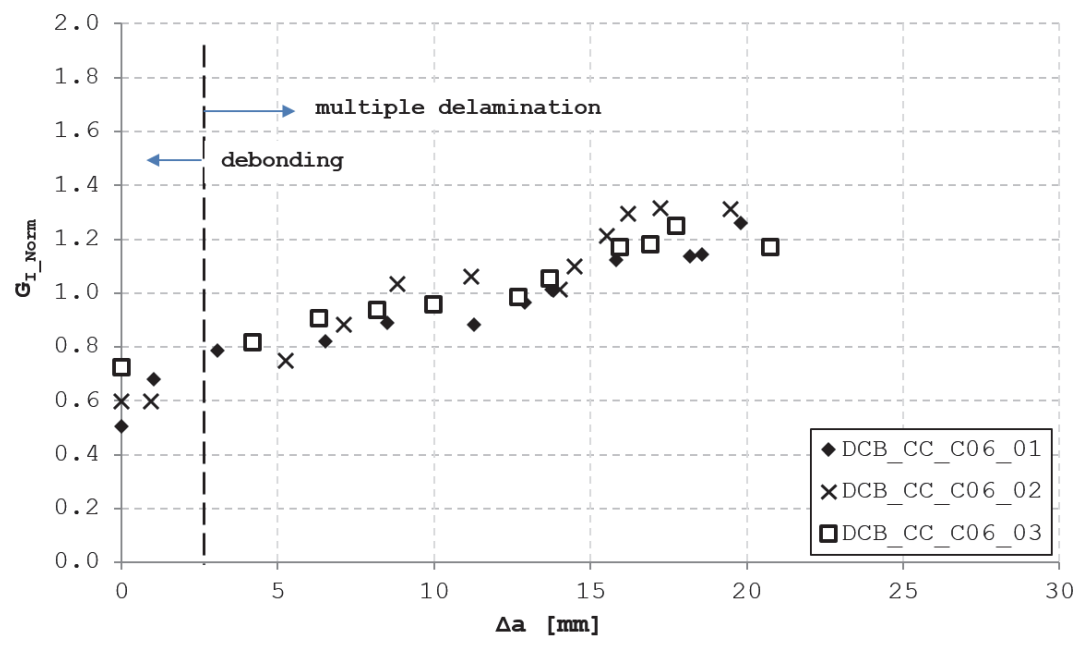

Figure 14: Mode I R-curve of CFRP-CFRP bonded joints.
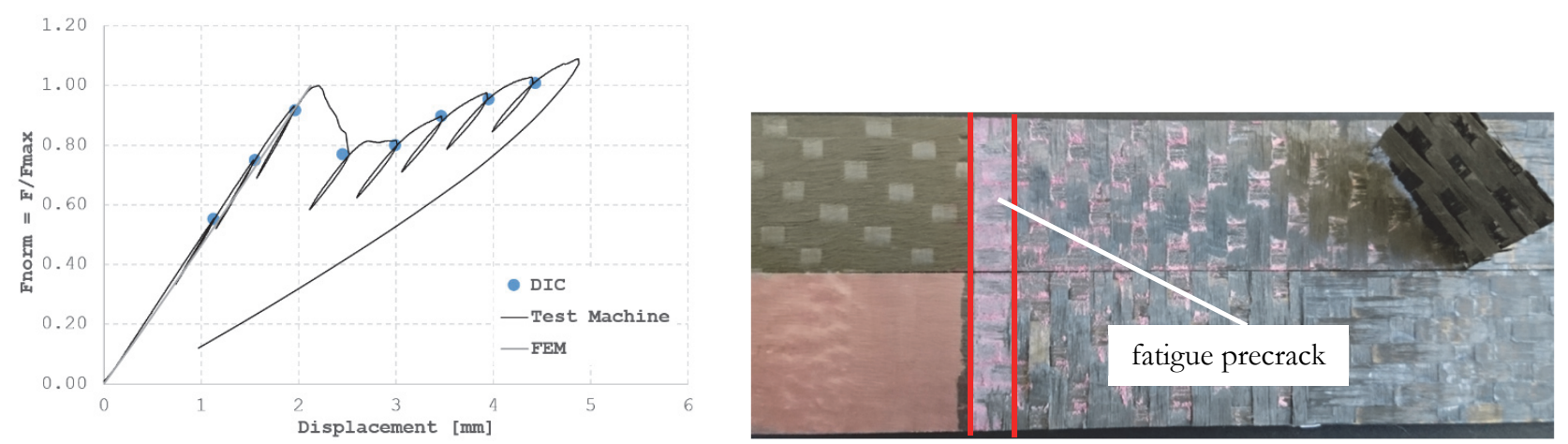

Figure 15: Example of force vs. opening behavior and fracture surface of massive CFRP-CFRP bonded joint ENF tests.

An example of Force vs. opening behavior and fracture surface of co-bonded ENF tests is shown in Fig. 15. Adhesive can be traced both at the beginning (fatigue precracking) and during the propagation phase. However, due to instability of the propagation phase of this test configuration, only one value of $\mathrm{G}_{\mathrm{II}}$ could be evaluated, that resulted 2.25 times higher than the value found in co-cured CFRP. Therefore, the adhesive yields a higher fracture toughness as expected since the crack is constrained within the adhesive layer differently from DCB test, where it jumps between the plies soon after the beginning of propagation. 
A reason of the different behavior in mode I and II can be found in the competition between composite resin and adhesive for the determination of the failure behavior. In fact, both TRAZ_CI and TRAZ_BJ tests yielded interlaminar failure of the CFRP. Therefore, under mode I loading the weakest region is the ply-to-ply interface and the adhesive cannot fully exploit its higher strength and (probably) fracture toughness with respect to the composite epoxy resin. On the other hand it is not yet fully understood why mode I CFRP delamination in bonded joint (see Fig. 14) occurs at GI slightly lower than in the co-cured CFRP. A first guess hypothesis is that the stress state in the delaminating plies at the crack tip region in the cocured and co-bonded specimens are not exactly the same, due to presence of a compliant adhesive layer. The presence of a small resin excess in co-cured CFRP and the possible mixing of pre-preg resin and adhesive during cure cycle in bonded joints are also factors that may contribute to that difference. Further investigation, including micrographic analysis is foreseen to highlight reasons of this behavior.

\section{CONCLUSIONS}

W

hen comparing to mode I and mode II fracture toughness co-cured and CFRP joints bonded with a structural adhesive film, the following conclusions can be drawn:

- tensile tests in the direction normal to the joint demonstrated that the tensile strength of the adhesive used here is higher than the ILTS of the composite;

- mode I fracture toughness and the R-curve of co-cured joints are higher than those of co-bonded joints. In both cases the increasing R-curve can be related to the development of multiple delaminations.

- the competition between composite resin and adhesive in determining the mode I failure behavior is determinant. From the tensile tests (i.e. under mode I loading), the weakest region can be located at the ply-to-ply interface and, therefore, the adhesive cannot improve the fracture toughness of the joint with respect to the co-cured joint since the crack skips the adhesive layer soon after the beginning of propagation;

- mode II fracture toughness of co-bonded joints is more than twice that of co-cured ones since the crack in this case moves within the adhesive layer, differently from mode I loading.

\section{REFERENCES}

[1] Vassilopoulos, A.P., Ed. (2015). Fatigue and Fracture of Adhesively Bonded Composite Joints, Cambridge (UK), Woodhead Publishing.

[2] Floros, I.S., Tserpes, K.I., Leobel, T. (2015). Mode-I, mode-II and mixed-mode I-II fracture behavior of composite bonded joints: Experimental characterization and numerical simulation, Composites Part B, 78, pp. 459-468.

[3] Li, J., Ying, Y., Zhang, T., Liang, Z. (2015). Experimental study of adhesively bonded CFRP joints subjected to tensile loads, International Journal of Adhesion \& Adhesives, 57, pp. 95-104.

[4] O'Dwyer, D.J., O'Dowd, N.P., McCarthy, C.T. (2013). Micromechanical investigation of damage processes at composite-adhesive interfaces, Composites Science and Technology, 86, pp. 61-69.

[5] Soykok, I.F. (2015). End geometry and pin-hole effects on axially loaded adhesively bonded composite joints, Composites Part B, 77, pp. 129-138.

[6] Camanho, P.P., Tong, L., Eds. (2011). Composite Joints and Connections, Cambridge (UK), Woodhead Publishing.

[7] Ascione, F. (2009). Ultimate behaviour of adhesively bonded FRP lap joints, Composites: Part B, 40, pp. 107-115.

[8] Renart, J., Costa, J., Sarrado, C., Budhe, S., Turon, A., Rodriguez-Bellido, A. (2015). In Vassilopoulos, A.P., Ed., Fatigue and Fracture of Adhesively Bonded Composite Joints, Cambridge (UK), Woodhead Publishing. 